Article

\title{
Biodegradation Studies of Novel Fluorinated Di-Vinyl Urethane Monomers and Interaction of Biological Elements with Their Polymerized Films
}

\author{
Yasaman Delaviz ${ }^{1}$, Meilin Yang ${ }^{2}$ and J. Paul Santerre ${ }^{1,2, *}$ \\ 1 Institute of Biomaterials and Biomedical Engineering, University of Toronto, \\ Toronto, ON M5G 1M1, Canada; y.delaviz@mail.utoronto.ca \\ 2 Faculty of Dentistry, University of Toronto, Toronto, ON M5G 1G6, Canada; \\ Meilin.Yang@dentistry.utoronto.ca \\ * Correspondence: paul.santerre@dentistry.utoronto.ca; Tel.: +1-416-946-8158; Fax: +1-416-979-4760
}

Received: 21 June 2017; Accepted: 11 August 2017; Published: 17 August 2017

\begin{abstract}
The monomeric components of resin composites in dental restorative materials are susceptible to hydrolysis in the oral cavity. The main objective of this study was to assess the bio-stability of fluorinated urethane dimethacrylates and determine the nature of fluoro-chemistry interactions with protein and bacterial adhesion (both sources of hydrolytic activity) onto cured resin. Degradation studies were performed in the presence of either albumin (in a mildly alkaline $\mathrm{pH}$ ) or cholesterol esterase (CE). The surface chemistry of the polymers was assessed by water contact angle measurements, pre- and post- incubation with albumin. Adhesion of Streptococcus mutans to cured resin was investigated. The fluorinated monomers were more stable against degradation when compared to the commercial monomer bisphenol A-diglycidyl methacrylate (BisGMA). While fluorinated monomers showed hydrolytic stability with respect to $\mathrm{CE}$, all fluorinated monomers underwent some degree of degradation with albumin. The fluoro-chemistry did not reduce protein and/or bacterial adhesion onto the surface, however post incubation with albumin, the fluorinated surfaces still presented hydrophobic character as determined by the high contact angle values ranging from $79^{\circ}$ to $86^{\circ}$. These monomers could potentially be used to increase the hydrophobicity of polymeric composites and provide a means to moderate esterolytic degradation associated with the monomeric component of the polymers within the oral cavity.
\end{abstract}

Keywords: fluorinated monomers; urethane; methacrylates; albumin; degradation; resin composites; proteins; surfaces

\section{Introduction}

Resin composites are among the most extensively used dental restorative materials despite having limited longevity in the oral cavity [1]. Resin composites are susceptible to hydrolysis, and the process is further catalyzed by salivary and bacterial derived enzymes [2-4]. Human saliva exhibits CE-like and pseudocholinesterase (PCE)-like hydrolase activities [2]. The esterase activity in saliva originates from different sources which includes epithelial cells, salivary glands, inflammatory response, and bacteria [5]. The highest fraction of esterase activity isolated from human saliva was found to be a mixture of proteins, among which albumin was identified as the leading protein with esterase activity that degrades BisGMA [4]. The esterase activity of albumin was enhanced with the formation of a complex containing Zinc- $\alpha 2$-glycoprotein, which can be simulated with slightly alkaline conditions [4]. Streptococcus mutans is another relevant source of esterase activity in the oral cavity that degrades resin composites and adhesive systems [3]. The rationale for improving the bio-stability of resin composites is thus supported by their degradation in the oral environment. 
In this study, both CE and albumin (in mildly alkaline environment) are used as physiologically relevant enzyme preparations to test the bio-stability of the newly synthesized fluorinated urethane monomers, and compare them to commercial BisGMA monomer.

The chemical composition of the monomers can ultimately define the bio-stability of the polymeric composites that arise from their polymerization. The enhanced stability observed with urethane-modified BisGMA when compared to BisGMA is believed to be facilitated by hydrogen bonded bridges between the urethane groups and the hydrolysable ester group [6]. As a result, a number of different urethane modified methacrylates have been synthesized [7-10]. Polar groups such as urethanes, esters, amides, and ethers are hydrophilic in nature and result in greater water sorption. To reduce water adsorption, pendant hydrophobic substituents can be incorporated into the backbone [11]. Another approach involves the use of fluorine-substitutes in the backbone or as side chains [9,12-14]. In addition to its hydrophobicity, fluorocarbon chains are bulkier than hydrocarbons [15], which can introduce steric hindrance. A number of fluoropolymers have presented greater resistance against bacterial adhesion due to their low surface energy [16-19]. However, such resistance to adhesion is not observed with all fluoropolymers, as Streptococcus gordonii and Streptococcus mutans have been shown to adhere to polytetrafluoroethylene (PTFE) [20,21].

New fluorinated urethane dimethacrylate monomers were synthesized for use in dental resin composites. The chemical structure of the monomers is provided in Figure 1. The monomers were synthesized using short chain ether and non-ether diols, perfluoroalcohols and lysine diisocyanate (LDI). The fluorinated groups have the potential to repel water and shield hydrolytically sensitive esters, while the urethanes generated from the isocyanates have the potential to yield H-bonding with the esters, further delaying the hydrolysis of ester moieties. Methacrylate moieties were incorporated using 2-hydroxyethyl methacrylate (HEMA) to allow for in situ vinyl polymerization chemistry, which is needed for practical use. The main objective of the present work was to investigate the protein based hydrolytic processes that could interact with different dimethacrylate urethane monomers containing hydrophobic fluorine groups in the vicinity of the hydrolytically sensitive chemical linkages, as illustrated in Figure 1. Since the susceptible linkages to hydrolysis in the polymers is equivalent to that of the monomeric form (e.g., the esters) in its formulations, degradation analysis is performed with the monomers in solution in order to achieve an accelerated investigation of differences between the susceptibility of monomeric components to degradation [4]. Degradation analysis using the monomers also reduces the numbers of parameters that must be controlled for which influence the degradation profile, this includes surface area, degree of filler loading, degree of polymerization, and extent of crosslinking [4]. Furthermore, it was a goal to characterize the influence of the fluorinated chemistry on bacterial adhesion behavior, when the bacteria were interacting with polymer resins generated from the fluorinated-urethane monomers.

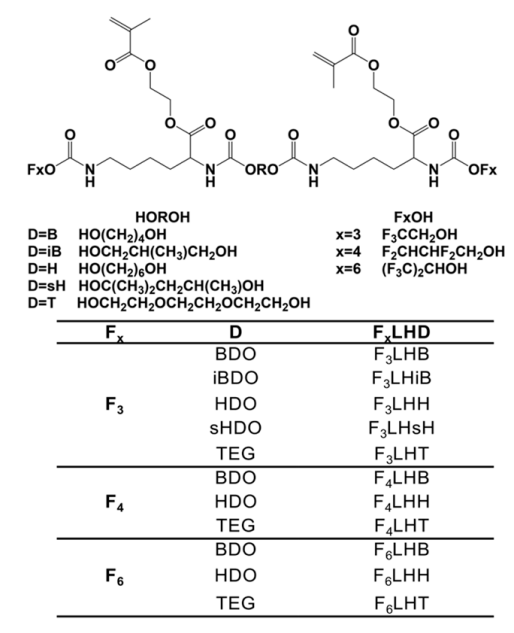

Figure 1. Schematic and nomenclatures of fluorinated monomers ( $\left.F_{x} L H D\right)$. 


\section{Materials and Methods}

All materials were purchased from Sigma-Aldrich Inc. (St. Louis, MO, USA) unless otherwise stated.

\subsection{Synthesis of Fluorinated Monomers}

Fluorinated hydrophobic monomers $\left(\mathrm{F}_{\mathrm{x}} \mathrm{LHD}\right)$ (see structure and nomenclature in Figure 1) were synthesized as previously described [22] using short chain ether and non-ether diols, perfluoroalcohols, and LDI with HEMA substituted for the methyl ester of LDI units to generate a di-vinyl monomer. The following reagents were used for the synthesis: dichloromethane (anhydrous, purity 99.8\%), 1,4-butanediol (purity $\geq 99 \%$ ), 2-methyl-1,3-propanediol (purity $\geq 99 \%$ ), 2-methyl-2,4-pentanediol (purity $\geq 99 \%$ ), triethylene glycol (purity 99\%), 1,6-hexanediol (purity 99\%), HEMA (purity 97\%), acetone (purity 99.5\%), chloroform (ACS reagent), dibutyltin dilaurate (purity 95\%), diethyl ether, 4-(dimethylamino) pyridine (purity $\geq 99 \%$ ), $N, N$-dimethylacetamide anhydrous (purity 99.8\%), 4-methoxyphenol (purity 99\%), 2,2,2-trifluoroethanol (purity $\geq 99 \%$ ), 2,2,3,3-tetrafluoro-1-propanol (purity 98\%), 1,1,1,3,3,3-hexafluoro-2-propanol (purity $\geq 99 \%$ ), hexane (purity $\geq 95 \%$ ), trifluoroacetic acid (purity 99\%), diethyl ether (purity 99.8\%), tert-butanol (purity 99.5\%), 1-ethyl-3-(3-dimethylamino-propyl) carbodiimide. $\mathrm{HCl}$ (Advanced ChemTech CreoSalus, Louisville, KY, USA), LDI (Daming Changda Co., Ltd., Daming, China), and alcalase (EMD Chemicals Inc., San Diego, CA, USA, activity 3.0264 U/mL, batch No. D00095203).

\subsection{Hydrolysis of Monomers in the Presence of Human Serum Albumin (HSA)}

Degradation studies were performed in protein solutions of $0.35 \mathrm{~g} \cdot \mathrm{L}^{-1}$ non-denatured HSA (Calbiochem 126654, purchased from EMD Chemicals Inc., San Diego, CA, USA) dissolved in a tris buffer ( $\mathrm{pH}$ 8.8). The buffer contained $20 \mathrm{mM}$ Trizma base, $2 \mathrm{mM}$ calcium chloride $\left(\mathrm{CaCl}_{2}\right), 5 \mathrm{mM}$ magnesium chloride $\left(\mathrm{MgCl}_{2}\right.$; BioShop, Burlington, $\mathrm{ON}$, Canada), with $\mathrm{pH}$ adjusted to 8.8 using $0.1 \mathrm{~N}$ hydrochloric acid and $0.1 \mathrm{~N}$ sodium hydroxide (BioShop, Burlington, ON, Canada) [4]. The protein solution was filtered using a Millex-GP $0.22 \mu \mathrm{m}$ syringe filters (Millipore, Bedford, MA, USA). Fluorinated monomers ( $\left.F_{x} L H D\right)$ (structure and nomenclature is described in Figure 1 ) and BisGMA (Esschem Inc., Linwood, PA, USA) were dissolved in HPLC grade methanol (MeOH; Caledon Laboratories Ltd., Georgetown, ON, Canada) separately at a concentration of $5 \mathrm{mM}$, and were then added to separate protein solutions to yield a final monomer concentration of $0.1 \mathrm{mM}$ with $2 \mathrm{vol} \%$ $\mathrm{MeOH}$. The solutions $(n=3)$ were then aliquoted into separate amber vials, with $0.5 \mathrm{~mL}$ of solution per vial for each time point, sealed and incubated at $37^{\circ} \mathrm{C}$. At specific time points $(0,1,2,3,4$, and 5 days), the corresponding vials were removed from the oven and $0.5 \mathrm{~mL}$ of $\mathrm{MeOH}$ was added to each vial and vortexed to denature the protein and cease the enzymatic activity. The solutions were then filtered using Amicon Ultra-0.5 centrifugal filtration units with $3 \mathrm{kDa}$ molecular weight cut off (Millipore, Bedford, MA, USA) for 30 min at 14,000 rcs (MPW-65R Centrifuge, Med Instrument, Warsaw, Poland) and at $8{ }^{\circ} \mathrm{C}$. The supernatant was collected and stored at $-20{ }^{\circ} \mathrm{C}$ until analysis. The experiment was repeated three times with triplicates $(n=9)$.

\subsection{Hydrolysis of Monomers in the Presence of CE}

$\mathrm{CE}$ solution was prepared by dissolving the required amount of powder enzyme (CE, Toyobo Co. COE-313, Osaka, Japan) in Dulbecco's phosphate-buffered saline (DPBS; Gibco, Grand Island, NY, USA). The CE activity was measured at $401 \mathrm{~nm}$ on a DU800 spectrophotometer (Beckman Coulter Inc., Fullerton, CA, USA), at $\mathrm{pH} 7.0$ and $37^{\circ} \mathrm{C}$ using 4-nitrophenylbutyrate (pNPB) as the substrate [23]. One unit of esterase activity was defined as generating $1 \mathrm{nmol} / \mathrm{min}$ of $p$-nitrophenol from $\mathrm{pNPB}$ at $\mathrm{pH} 7.0$ [24]. Select synthesized fluorinated monomers $\left(\mathrm{F}_{3} \mathrm{LHT}, \mathrm{F}_{6} \mathrm{LHT}\right)$ and a commercial control monomer BisGMA were dissolved in $\mathrm{MeOH}$ and diluted with DPBS to yield a final concentration of $\sim 0.01 \mathrm{mM}$. From each monomer solution $(\sim 0.01 \mathrm{mM}), 2 \mathrm{~mL}$ were added to 
15 separate vials giving a total of 45 vials per monomer condition $(n=3)$. To each vial, $C E$ solution was added to yield an activity of 5 units $/ \mathrm{mL}$, and the vials were incubated in an oven at $37^{\circ} \mathrm{C}$ for $24 \mathrm{~h}$. At specific time points $(1,4,8,10$ and $24 \mathrm{~h}), 3$ vials for each monomer condition were removed from the oven and $133 \mu \mathrm{L}$ of $\mathrm{MeOH}$ was added to denature the enzyme and cease the esterolytic activity [5].

\subsection{High Performance Liquid Chromatography (HPLC)}

Degradation solutions were analyzed using a Waters ${ }^{\mathrm{TM}}$ HPLC system (Mississauga, ON, Canada) equipped with a 600E multi-solvent delivery system and 996 photodiode array (PDA) detector connected to a data acquisition system, and signals were processed using Empower Software (Waters Corporation, Milford, CT, USA). Samples $(50 \mu \mathrm{L})$ were injected into a Kinetex ${ }^{\mathrm{TM}}$ C18 column (Phenomenex 00D-4462-E0, Torrance, CA, USA) using an 800 series Hamilton syringe (Hamilton Company, Reno, NV, USA). Solutions were eluted through the system at a flow rate of $1.0 \mathrm{~mL} / \mathrm{min}$ with helium gas running through the mobile phase at a sparge rate of $60 \mathrm{~mL} / \mathrm{min}$. A gradient method was used beginning with $30: 70 \mathrm{vol} \%$ of MeOH: $20 \mathrm{mM}$ ammonium acetate (AnalaR, BDH Inc., Toronto, ON, Canada) buffer to $100 \% \mathrm{MeOH}$ for $7 \mathrm{~min}$. The peak areas for the $\mathrm{F}_{\mathrm{x}} \mathrm{LHD}$ monomers were measured at a retention time of approximately $3 \mathrm{~min}$ and $215 \mathrm{~nm} \mathrm{~h}$. For BisGMA, the gradient method was followed by elution with $100 \% \mathrm{MeOH}$ for $8 \mathrm{~min}$, and the peak area was measured for a retention time of $11 \mathrm{~min}$ at $280 \mathrm{~nm}$. HPLC chromatograph for each monomer at day 0 is available in the supplementary information (Figures S1 and S2). Before every injection, the pressure was equilibrated by running the initial mobile phase (30 vol \% MeOH-70 vol \% buffer) for $5 \mathrm{~min}$. When analyzing samples incubated in the presence of $\mathrm{CE}$, a previously developed method consisting of Luna $5 \mu \mathrm{m}$ C18 100A $250 \times 4.60 \mathrm{~mm}$ column (Phenomenex, Torrance, CA, USA) was used [5].

\subsection{Preparation of Polymerized Monomer Resins}

Camphorquinone (CQ) and 2-(dimethylamino) ethyl methacrylate (DMAEM) were used as the photo-initiator system. For the polymerization of resins, $0.45 \mathrm{~g}$ of monomer was blended with $28.8 \mu \mathrm{L}$ of initiator solution composed of $0.2 \mathrm{~g} \mathrm{CQ}, 0.4 \mathrm{~g}$ DMAEM, and $3.6 \mathrm{~mL}$ DriSolv ${ }^{\circledR}$ dichloromethane (EMD Millipore, Bedford, MA, USA). The solutions were left to mix overnight with aluminum foil wrapped around the vials to protect against pre-mature polymerization. The mixtures were formed in cylindrical Teflon ${ }^{\mathrm{TM}}$ molds ( $3 \mathrm{~mm}$ diameter $\times 1 \mathrm{~mm}$ height or $5 \mathrm{~mm}$ diameter $\times 1 \mathrm{~mm}$ height) and the solvent was left to evaporate at room temperature for at least $15 \mathrm{~min}$ while being protected from direct light. Mylar ${ }^{\mathrm{TM}}$ strips were placed over the Teflon ${ }^{\mathrm{TM}}$ molds and polymerization was photo-initiated using a dental blue light, either a FLASHlite 2.0 or Sapphire plus (DenMat, Santa Maria, CA, USA), at room temperature for $1 \mathrm{~min}$ per side. The photo-polymerized cylindrical samples were subsequently post cured for $24 \mathrm{~h}$ in the oven at $60 \pm 5^{\circ} \mathrm{C}$.

\subsection{Water Contact Angle Measurement and Indirect Measurement of Protein Adhesion}

Thin films of material were cured on glass slides (VWR International, Mississauga, ON, Canada) using the same initiator system and polymerization as described above. Slides were post cured in the oven at $60 \pm 5{ }^{\circ} \mathrm{C}$ overnight, and allowed to reach room temperature prior to contact angle measurements. The advancing and receding contact angles of water on the film surfaces were determined using a contact angle goniometer (NRL Model 100-00, Ramé-Hart, Inc., Mountain Lakes, NJ, USA). Commercial monomers BisGMA and urethane dimethacrylate (UDMA; Esschem Inc., Linwood, PA, USA) were used as controls for relative comparison. Measurements were done by placing a droplet of MilliQ water using a micro-syringe on the polymers' surfaces, and the contact angle was recorded for either side of the droplet. The average value was used for a single measurement. For each material, 3 polymer films were prepared with at least 5 drops per film recorded.

After contact angle measurements were recorded, the polymer films were exposed to $1 \mathrm{~g} \cdot \mathrm{L}^{-1}$ bovine serum albumin (BSA) solution prepared in DPBS for $45 \mathrm{~min}$ at room temperature. Samples were rinsed several times with distilled water to remove non-adhered proteins, and left in the fridge 
for $72 \mathrm{~h}$. Polymer samples were removed from the fridge and allowed to reach room temperature prior to repeating the contact angle measurements.

\subsection{Direct Measurement of Protein Adhesion Assay}

Cylindrical polymer specimens were first incubated in $70 \%$ ethanol overnight to extract potential unreacted monomer or initiator from the polymeric material. Subsequently, the ethanol was removed and samples were left to dry in the biosafety cabinet for $4 \mathrm{~h}$. Samples were then incubated with $1 \mathrm{~g} \cdot \mathrm{L}^{-1}$ HSA in DPBS for $1 \mathrm{~h}$ at $37^{\circ} \mathrm{C}$, rinsed three times with DPBS and placed into new wells. The adsorbed proteins were then eluted at room temperature using $2 \%$ sodium dodecyl sulfate (SDS; BioShop, Burlington, ON, Canada) under gentle shaking on a shaker plate for $24 \mathrm{~h}$. The resulting recovered solutions were assessed for total protein content using a micro bicinchoninic acid (BCA) protein assay (Thermo Scientific, Rockford, IL, USA).

\subsection{Colony Forming Unit (CFU) Counts}

Bacterial adhesion onto polymerized cylindrical specimens was assessed under static conditions. Streptococcus mutans UA159 stored in $20 \%$ glycerol broth at $-80{ }^{\circ} \mathrm{C}$ were recovered and sub-cultured on Todd-Hewitt (TH) agar plates with $0.3 \%$ yeast extract (BioShop, Burlington, ON, Canada) and incubated for $48 \mathrm{~h}$ at $37^{\circ} \mathrm{C}$ and $5 \% \mathrm{CO}_{2}$. Todd-Hewitt yeast extract (THYE) broth was prepared from $30 \mathrm{~g} \cdot \mathrm{L}^{-1} \mathrm{TH}$ and $3 \mathrm{~g} \cdot \mathrm{L}^{-1}$ yeast extract, with the addition of $18 \mathrm{~g} \cdot \mathrm{L}^{-1}$ agar (BioShop, Burlington, ON, Canada), when preparing THYE agar plates. Several well-isolated colonies were removed from the plate and inoculated into fresh THYE broth medium and incubated overnight at $37{ }^{\circ} \mathrm{C}$ and $5 \% \mathrm{CO}_{2}$. The overnight solutions were diluted in a 1:10 dilution with THYE medium. After aging the specimens in DPBS for $48 \mathrm{~h}$ to condition the polymer surfaces and extract potential unreacted monomers from the samples, the cured cylindrical specimens were placed in a 96 well plate with $200 \mu \mathrm{L}$ of the 1:10 diluted overnight solution. The specimens were incubated with bacteria for $24 \mathrm{~h}$ at $37^{\circ} \mathrm{C}$, upon which samples were rinsed three times with sterile DPBS to remove non-adhered bacteria cells. Subsequently, each specimen was added to a sterile container with DPBS and placed in an ultrasonic bath (Bransonic 2510 Ultrasonic cleaner, Danbury, CT, USA, $42 \mathrm{kHz} \pm 6 \%$ ) and sonicated for $1 \mathrm{~min}$ to recover the adhered bacteria $[25,26]$. The solutions were then serially diluted and plated onto THYE agar plates followed by $48 \mathrm{~h}$ of incubation at $37^{\circ} \mathrm{C}$ and $5 \% \mathrm{CO}_{2}$. The $\mathrm{CFU}$ of the disrupted biofilm cultures recovered were then counted after $48 \mathrm{~h}$ of incubation.

\subsection{Statistical Analysis}

All statistical analyses were performed using IBM SPSS program (IBM Corp., Armonk, NY, USA, version 20.0). One-way ANOVA was performed after verifying homogeneity of variance (Leven's test) for albumin and $S$. mutans adhesion. For contact angle measurements, student's $t$-test was used to determine the statistical significance of any difference between the mean values of pre- to post-incubation conditions for advancing and receding values. To compare the different polymeric surfaces, a Welch ANOVA was used with Games-Howell post-hoc analysis. For biodegradation studies, paired $t$-test was used to compare the percent residual of each monomer relative to its non-degraded concentration at different time points. One-way ANOVA with Tukey post-hoc analysis was performed after verifying homogeneity of variance (Leven's test) to compare the percent residual for the different monomers. The significant threshold was set to $\propto=0.05$ for all analyses.

\section{Results}

Over the course of the first two days of monomer degradation during incubation in HSA at $\mathrm{pH} 8.8$, the level of native $\mathrm{F}_{3}$-type fluoro-monomer had remained close to $90 \%$, whereas the BisGMA control had already dropped to less than $70 \%$ of the original monomer level, significantly $(p<0.05)$ lower than the $\mathrm{F}_{3}$-type fluoro-monomers (Figure 2). Significant loss of original monomer began at the $72 \mathrm{~h}$ time point for several of the $\mathrm{F}_{3}$ fluoro-monomers and showed a continued loss over time. 
After 5 days of incubation, the percent residual BisGMA was significantly lower $(p<0.05)$ than $\mathrm{F}_{3} \mathrm{LHB}$, $\mathrm{F}_{3} \mathrm{LHH}$, and $\mathrm{F}_{3} \mathrm{LHsH}$, which had as much as $20 \%$ more residual monomer (Figure 2).

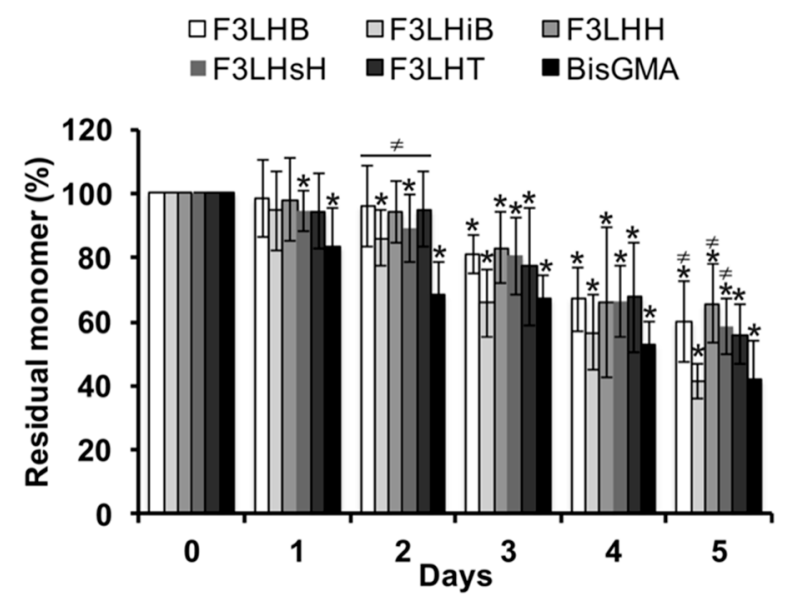

Figure 2. Monomer Degradation. Residual monomer in the biodegradation solution incubated with $0.35 \mathrm{~g} \cdot \mathrm{L}^{-1} \mathrm{HSA}$ at $\mathrm{pH} 8.8(n=9, \pm$ standard deviation $(\mathrm{SD})) .{ }^{*}$ Denotes significant difference $(p<0.05)$ from Day 0 . For a given time point, $\neq$ denotes significant difference $(p<0.05)$ from BisGMA.

Figure 3 shows the relative slopes of all $\mathrm{F}_{\mathrm{x}} \mathrm{LHD}$ monomers that underwent degradation in the presence of HSA at $\mathrm{pH}$ 8.8, from which degradation rates were calculated. The percent loss of monomer per day was greatest for BisGMA $\left(12 \%, R^{2}=0.957\right)$, followed by $\mathrm{F}_{3} \mathrm{LHiB}\left(11 \%, R^{2}=0.958\right)$, $\mathrm{F}_{4} \mathrm{LHB}\left(10 \%, R^{2}=0.985\right), \mathrm{F}_{3} \mathrm{LHT}\left(8 \%, \mathrm{R}^{2}=0.905\right), \mathrm{F}_{6} \mathrm{LHH}\left(8 \%, R^{2}=0.963\right), \mathrm{F}_{3} \mathrm{LHsH}\left(8 \%, R^{2}=0.959\right)$, $\mathrm{F}_{3} \mathrm{LHB}\left(7 \%, R^{2}=0.878\right), \mathrm{F}_{6} \mathrm{LHT}\left(7 \%, R^{2}=0.948\right), \mathrm{F}_{3} \mathrm{LHH}\left(7 \%, R^{2}=0.882\right), \mathrm{F}_{6} \mathrm{LHB}\left(7 \%, R^{2}=0.987\right)$, $\mathrm{F}_{4} \mathrm{LHH}\left(6 \%, R^{2}=0.908\right)$, and $\mathrm{F}_{4} \mathrm{LHT}\left(5 \%, R^{2}=0.837\right)$. Comparing the degradation profile of $\mathrm{F}_{\mathrm{x}} \mathrm{LHT}$ to $\mathrm{F}_{\mathrm{x}} \mathrm{LHH}$ monomers suggests that the hydrophobicity of the core does not significantly $(p>0.05)$ influence the degradation of the monomer components in solution (Figure 3). The $\mathrm{F}_{\mathrm{x}} \mathrm{LHT}$ monomers contain the hydrophilic triethylene glycol and the $\mathrm{F}_{\mathrm{x}} \mathrm{LHH}$ monomers contain the hydrophobic 1,6-hexane as the core (Figure 1). Increasing the fluorine-content from $\mathrm{F}_{3}$ to $\mathrm{F}_{6}$ was also not found to significantly $(p>0.05)$ alter the hydrolysis rate of the monomers in solution (Figure 3$)$, although select combinations of fluoro and dihydroxyl spacers did yield up to two-times lower degradation rates than the commercial BisGMA.

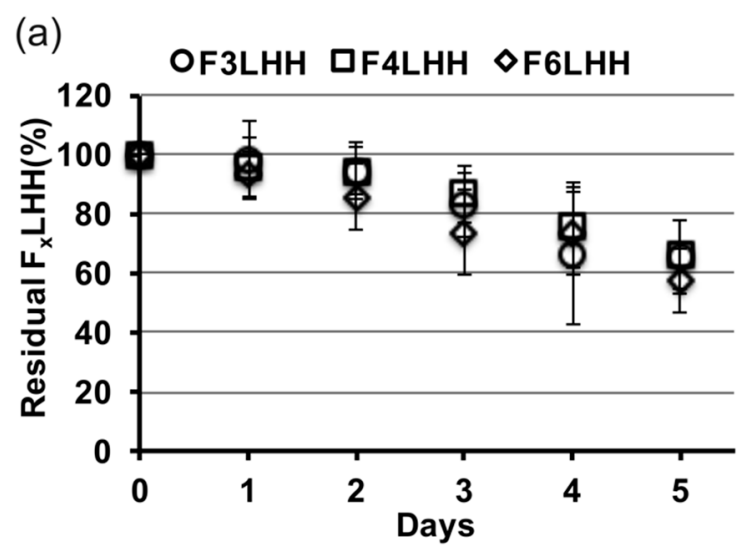

Figure 3. Cont. 
(b)

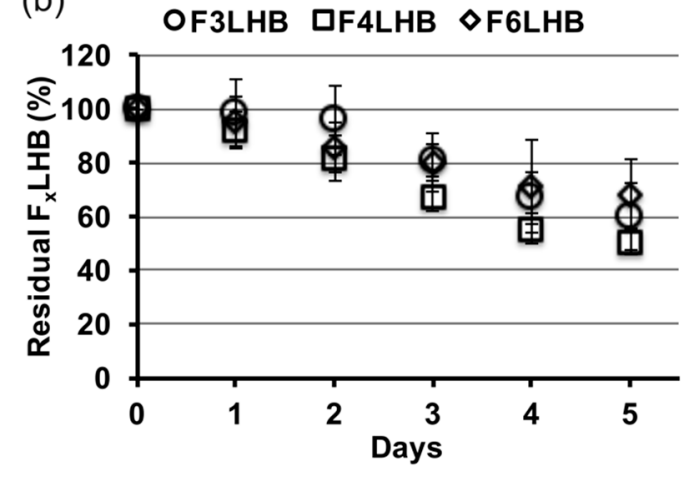

(c)

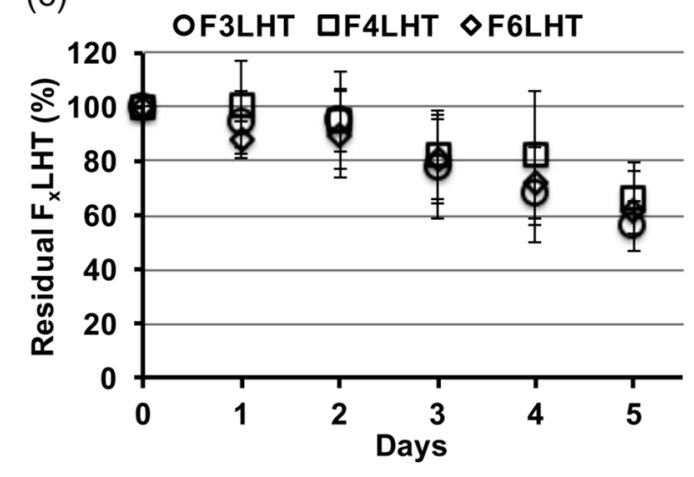

Figure 3. Residual $\mathrm{F}_{\mathrm{X}} \mathrm{LHD}$ monomer in the biodegradation solution incubated with $0.35 \mathrm{~g} \cdot \mathrm{L}^{-1} \mathrm{HSA}$ at $\mathrm{pH} 8.8$ ( $n=9, \pm \mathrm{SD})$, arranged based on the nature of diol linkers: (a) hexane diol $\left(\mathrm{F}_{\mathrm{x}} \mathrm{LHH}\right)$; (b) butane diol ( $\left.F_{x} L H B\right)$; and $(c)$ triethylene glycol $\left(F_{x} L H T\right)$.

Two of the more stable monomers were also examined for their relative stability towards CE (Figure 4), which is an enzyme-like activity that has been found in saliva to be highly active towards the commercial monomer BisGMA [2,4]. Within $24 \mathrm{~h}$ of exposure to CE, BisGMA had undergone degradation by $79 \%$ and produced equivalent molar amounts of bisphenol A bis (2,3-dihydroxypropyl) ether (BisHPPP), the terminal degradation by-product. However, $\mathrm{F}_{3} \mathrm{LHT}$ and $\mathrm{F}_{6} \mathrm{LHT}$ showed no visible biodegradation under the same in vitro condition (Figure 4). These findings further suggest that hydrogen bonding moieties and the hydrophobic fluorine atoms possibly were able to provide an initial protection of the ester linkage against degradation in DPBS with the presence of active CE.

The polymers generated from the monomers were then characterized for their interaction with water and protein. All of the fluorine containing polymers $\left(\mathrm{pF}_{x} \mathrm{LHD}\right)$ showed significantly higher $(p<0.05)$ advancing contact angles when compared to the two non-fluorinated polymer controls (Table 1). The change in advancing contact angle value for the $F_{x} L H D$ films upon exposure to albumin was less than $\sim 5^{\circ}$, but more than $10^{\circ}$ for the non-fluorinated controls. Similarly, the change in receding contact angles for the fluorinated materials were less than $5^{\circ}$, whereas the two controls showed significant drops in receding contact angles implying a substantially more hydrophilic substrate $\left(16^{\circ}\right.$ for $\mathrm{pBisGMA}$ and $14^{\circ}$ for pUDMA respectively). The hysteresis values before and after incubation with albumin were within a similar range of $30^{\circ}$ to $40^{\circ}$ for the $\mathrm{pF}_{\mathrm{x}} \mathrm{LHD}$ films, suggesting that the heterogeneous nature of the polar and apolar group were not affected upon exposure to the protein solution. Contact angle hysteresis was greater on $\mathrm{pF}_{\mathrm{x}} \mathrm{LHD}$ samples relative to the non-fluorinated controls pBisGMA and pUDMA, implying greater surface dynamics on the fluorinated samples. The elevated advancing values $\left(79^{\circ}\right.$ to $\left.86^{\circ}\right)$ after incubation with albumin indicates that the hydrophobic fluorine groups are likely still present and influencing the surface after exposure to albumin, therefore maintaining the hydrophobic surface chemistry that was incorporated to enhance the stability against hydrolysis. 


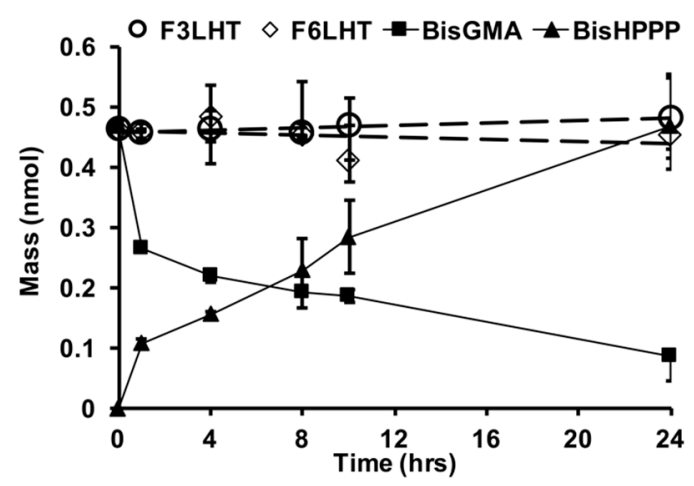

Figure 4. Hydrolytic degradation studies of two select fluorinated monomers $\left(\mathrm{F}_{3} \mathrm{LHT}\right.$ and $\left.\mathrm{F}_{6} \mathrm{LHT}\right)$ vs. BisGMA in the presence of 5 units $/ \mathrm{mL} \mathrm{CE}$, at $37^{\circ} \mathrm{C}(n=3, \pm \mathrm{SD})$.

Table 1. Contact angle $\left(^{\circ}\right)$ measurements are reported with \pm SD for films before and after exposure to albumin (see nomenclature for chemical structures in Figure 1). * denotes significance difference $(p<0.05)$ from pre-incubation value.

\begin{tabular}{|c|c|c|c|c|c|c|}
\hline \multirow[t]{2}{*}{ Sample } & \multicolumn{3}{|c|}{ Pre-Incubation } & \multicolumn{3}{|c|}{ Post-Incubation with BSA } \\
\hline & Advancing & Receding & Hysteresis & Advancing & Receding & Hysteresis \\
\hline $\mathrm{pF}_{3} \mathrm{LHB}$ & $85( \pm 3)$ & $49( \pm 4)$ & 36 & $86( \pm 4)$ & $46( \pm 7)$ & 40 \\
\hline $\mathrm{pF}_{4} \mathrm{LHB}$ & $88( \pm 3)$ & $49( \pm 4)$ & 39 & $83( \pm 2) *$ & $45( \pm 3) *$ & 38 \\
\hline $\mathrm{pF}_{6} \mathrm{LHB}$ & $86( \pm 2)$ & $50( \pm 4)$ & 36 & $85( \pm 3)$ & $45( \pm 3) *$ & 40 \\
\hline $\mathrm{pF}_{3} \mathrm{LHiB}$ & $85( \pm 3)$ & $49( \pm 5)$ & 36 & $81( \pm 2) *$ & $48( \pm 4)$ & 33 \\
\hline $\mathrm{pF}_{3} \mathrm{LHH}$ & $84( \pm 2)$ & $49( \pm 4)$ & 35 & $81( \pm 2) *$ & $48( \pm 2)$ & 33 \\
\hline $\mathrm{pF}_{4} \mathrm{LHH}$ & $84( \pm 3)$ & $51( \pm 5)$ & 33 & $83( \pm 2)$ & $51( \pm 4)$ & 32 \\
\hline $\mathrm{pF}_{6} \mathrm{LHH}$ & $81( \pm 1)$ & $47( \pm 4)$ & 34 & $82( \pm 2)$ & $43( \pm 4) *$ & 39 \\
\hline $\mathrm{pF}_{3} \mathrm{LHsH}$ & $85( \pm 3)$ & $49( \pm 4)$ & 36 & $81( \pm 2)$ * & $44 \pm 5) *$ & 37 \\
\hline $\mathrm{pF}_{3} \mathrm{LHT}$ & $86( \pm 3)$ & $50( \pm 4)$ & 36 & $84( \pm 4)$ & $53( \pm 4)$ * & 31 \\
\hline $\mathrm{pF}_{4} \mathrm{LHT}$ & $81( \pm 2)$ & $40( \pm 5)$ & 41 & $79( \pm 2)$ * & $39( \pm 3)$ & 40 \\
\hline $\mathrm{pF}_{6} \mathrm{LHT}$ & $83( \pm 4)$ & $40( \pm 5)$ & 43 & $80( \pm 4)$ & $42( \pm 4)$ & 38 \\
\hline pBisGMA & $72( \pm 4)$ & $52( \pm 4)$ & 20 & $58( \pm 3)$ * & $36( \pm 3) *$ & 22 \\
\hline pUDMA & $75( \pm 2)$ & $49( \pm 4)$ & 26 & $65( \pm 4)$ * & $35( \pm 5)^{*}$ & 30 \\
\hline
\end{tabular}

A select number of polymers made from $\mathrm{F}_{\mathrm{x}} \mathrm{LHD}$ monomers containing hydrophobic cores $\left(\mathrm{F}_{3} \mathrm{LHB}\right.$, $\mathrm{F}_{3} \mathrm{LHH}$, and $\mathrm{F}_{3} \mathrm{LHsH}$ ) were used to determine whether the high advancing contact angle values observed on the $\mathrm{pF}_{\mathrm{x}} \mathrm{LHD}$ films after exposure to albumin were related to surface chemistry or resistance to protein adhesion. HSA was found to adhere to all three fluorinated polymer surfaces, similar to the non-fluorinated polymer controls (Figure 5), suggesting that the high advancing values are related to hydrophobic chemical groups present at the surface rather than resistance to protein adsorption.

The influence of the polymers' fluoro-content from the pendant structures $\left(\mathrm{F}_{3}, \mathrm{~F}_{4}\right.$, and $\left.\mathrm{F}_{6}\right)$ on bacterial adhesion was studied using polymers made from the $\mathrm{F}_{\mathrm{x}} \mathrm{LHB}$ monomers and compared to the non-fluorinated controls. S. mutans were found to adhere to all studied polymer surfaces with no significant difference in the adhered CFU (Figure 6), suggesting that the fluoro-chemistry was inadequate in overcoming bacterial attachment to cured specimens. 


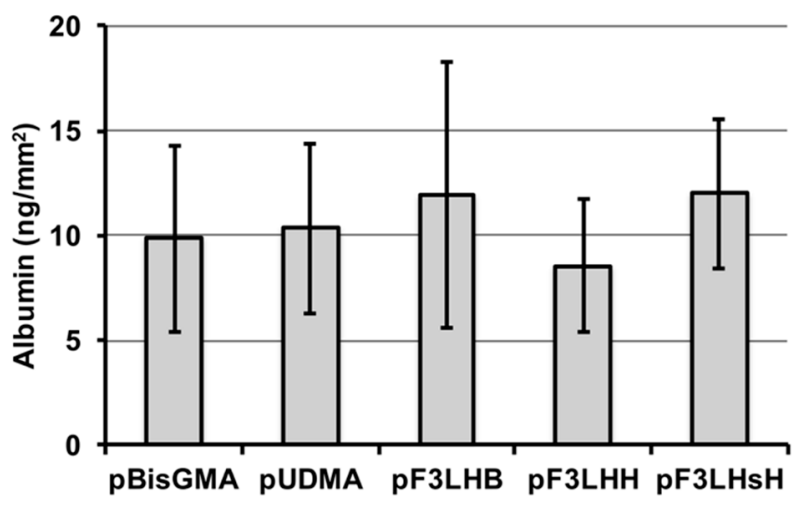

Figure 5. Albumin (HSA) adsorption following $1 \mathrm{~h}$ of incubation and $24 \mathrm{~h}$ of elution with $2 \%$ SDS solution for select fluorinated polymers and controls $(n=14, \pm \mathrm{SD})$.

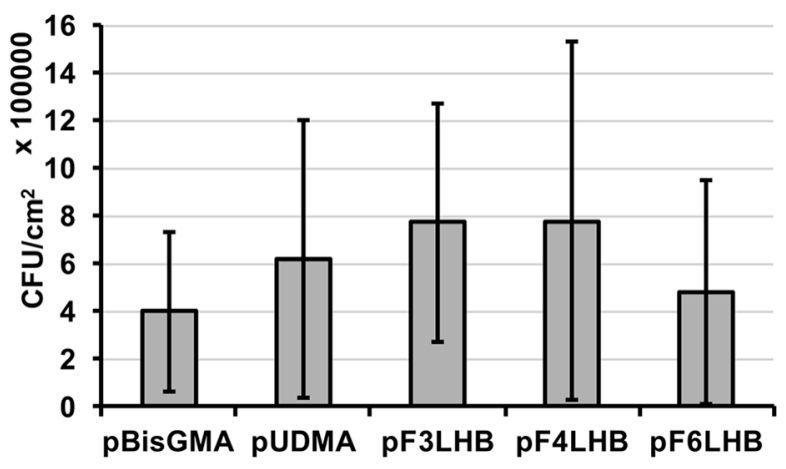

Figure 6. Adhered S. mutans after $24 \mathrm{~h}$ of incubation at $37^{\circ} \mathrm{C}$ in $5 \% \mathrm{CO}_{2}$ under static conditions for select fluorinated polymers and controls $(n=14, \pm \mathrm{SD})$.

\section{Discussion}

Fluorine atoms occupy a larger volume than hydrogen atoms because of the larger van der Waals radius. Fluoro-chains are also bulkier and more rigid than hydrocarbons [27], which may shield the susceptible ester linkages of the vinyl resin monomers from esterolytic degradation. In the mildly alkaline solution with the presence of HSA all fluoro-monomers underwent some degree of degradation, suggesting that the fluoro-chemistry was unable to fully shield all susceptible linkages from hydrolysis. However, the majority of the $\mathrm{F}_{\mathrm{x}} \mathrm{LHD}$ monomers still presented greater stability against hydrolytic degradation when compared to the commercial monomer BisGMA. The biodegradation studies with albumin were done in a mildly alkaline environment $(\mathrm{pH} 8.8)$ as the esterolytic activity of albumin has been shown to become more potent at this $\mathrm{pH}$ [4]. The concentration of albumin used in the current study was selected to generate the equivalent of 5 units/mL CE-like activity with respect to $\mathrm{PNPB}$ to simulate the esterase activity found in human saliva [23].

In the presence of $\mathrm{CE}$, the selected monomers $\mathrm{F}_{3} \mathrm{LHT}$ and $\mathrm{F}_{6} \mathrm{LHT}$ were found to have significantly greater stability against degradation when compared to BisGMA over $24 \mathrm{~h}$. CE is an inflammatory cell derived enzyme that preferentially catalyzes the hydrolysis of long-chain fatty acid esters of cholesterol [2]. The catalytic reactivity of CE on a synthetic substrate depends on the ester side-chain, for example higher hydrolysis rates are observed with longer hydrocarbon side chains (butyrate vs. acetate) [2]. Components of human saliva exhibit CE-like behavior, which preferentially degrade the aromatic monomer BisGMA versus triethylene glycol dimethacrylate, another commercially used monomer, and similar behavior is also observed with pure CE [23]. Similar to BisGMA, triethylene glycol dimethacrylate has been shown to undergo complete hydrolysis within $25 \mathrm{~h}$ in the presence of human saliva derived esterase activity [5]. Despite the difference 
in chemical structure, both monomers contain relatively unhindered esters that readily undergo hydrolysis in the presence of esterases. UDMA, another commonly used monomer that contains urethane bonds, has greater stability against hydrolysis when compared to BisGMA. In human saliva, BisGMA undergoes complete hydrolysis by $48 \mathrm{~h}$ while after $72 \mathrm{~h}$ of incubation more than $70 \%$ of UDMA is still left in solution [28]. Work by Hagio et al. [28] has shown that modifying BisGMA by replacing the hydroxyl moieties with short hydrocarbon side chains coupled via a urethane bond increases the hydrolytic stability in the presence of human saliva [28]. The enhanced stability was attributed to the difference in molecular structure, such as steric hindrance and the addition of the urethane bonds. The faster hydrolysis observed with BisGMA in the current study may therefore be related to the unhindered ester bonds available for hydrolysis and substrate preference for $\mathrm{CE}$, while greater stability with the $\mathrm{F}_{\mathrm{x}} \mathrm{LHD}$ monomers may be resulting from the branched structure and bulky fluoro groups creating steric hindrance for the enzyme to act on the esters.

The resulting polymers are expected to have diverse surface chemistries within their individual surfaces as all of the polymerized monomers contain non-polar and polar moieties, the latter resulting from polar carbonyl and urethane bonds in the urethane based monomers and polar carbonyl and hydroxyl moieties in BisGMA. The higher hysteresis observed with the $\mathrm{pF}_{\mathrm{x}} \mathrm{LHD}$ suggests a greater heterogeneity in the surface of the $\mathrm{pF}_{\mathrm{x}} \mathrm{LHD}$ films, most likely related to having hydrophobic fluorine chemistry and polar moieties present within the monomers making up the surface. Changing the form of the fluoro-content from $\mathrm{F}_{3}$ to $\mathrm{F}_{6}$ structures did not further increase the advancing contact angle values. This may have possibly been due to a saturation of the effect for the fluorine chemistry relative to the presence of the remaining non-fluorinated chemistry resulting from the heterogeneity of other chemistries at the surfaces of the $\mathrm{pF}_{\mathrm{x}} \mathrm{LHD}$ films. The high advancing contact angle values, even after exposure to albumin, suggest that the fluoro-chemistry's influence remains present at the surface, which may provide a means to influence esterolytic activities generated by bacterial and salivary derived enzymes when interacting with resin composite.

All of the polymer surfaces studied were hydrophobic based on their advancing contact angle values being greater than $65^{\circ}$ [29]. The adhesion of proteins and bacteria onto the polymer surfaces is highly affected by surface chemistry and wettability [30]. The adsorption process can involve different types of interaction including van der Waals, hydrogen bonding, hydrophobic and electrostatic interactions [31]. Hydrophobic interactions generally result in hydrophobic surfaces being more protein-adsorbent when compared to hydrophilic surfaces that are protected through repulsive solvation forces from the strongly bound water to the surface [32]. Similar to protein adhesion, hydrophobic surfaces are less resistant to bacterial adhesion [21]. However, super hydrophobic surfaces containing siloxane and fluorosiloxane have been shown to reduce protein adsorption and bacterial adhesion [33]. However, PTFE surfaces and resin composites with PTFE particle additives have been unable to inhibit protein adsorption and bacterial adhesion $[20,21]$. Similar to the PTFE surfaces, albumin was found to adhere to the $\mathrm{pF}_{\mathrm{x}} \mathrm{LHD}$ surfaces. Proteins adsorb to polymer surfaces in different conformations and orientations depending on the surface chemistry and physical properties [31]. The high advancing contact angle values after exposure to BSA for the fluorinated surfaces suggests that the manner in which the proteins have adsorbed to the $\mathrm{pF}_{x}$ LHD surfaces is different from that of the non-fluorinated controls. One hypothesis is that along with the hydrophobic fluoro chemistry at the polymer surface, BSA may be selectively interacting with the polar groups on the $\mathrm{F}_{\mathrm{x}} \mathrm{LHD}$ derived polymers and enabling a hydrophobic presentation of the protein to the water droplet. In contrast, the hydrophobic interactions between the polymeric material and protein may be more dominant on the non-fluorinated surfaces with the protein's polar groups being presented towards the water droplet, resulting in a more hydrophilic surface with significantly lower advancing and receding contact angle values post incubation. With such a differentiated interaction of albumin at the fluorinated polymer surfaces in play, then it becomes possible to rationalize the divergent outcomes of the esterolytic activities with the fluorinated monomer components observed in the earlier studies, and specifically those of albumin, as conformational structure is critically important to its hydrolytic activity in mildly 
basic conditions [4]. More precisely, the albumin associated esterase activity is dependent on the ligand binding sites of Tyr-411 and Arg-410 [34]. A substrate combines rapidly and reversibly to Tyr-411 and Arg-410, and the hydroxyl group of Ser-489 and the aromatic residue of Phe- 488 help to stabilize the albumin-substrate intermediate. Both the arginine and serine amino-acid moieties are polar and could be hindered in their interaction with polar urethane groups of the fluorinated monomers. In combination with the water repelling character of the surfaces generated from the polymerized fluorinated monomers, even in the presence of albumin (Table 1), hydrolytic reactions would be hindered for the monomeric components as seen in Figures 2 and 3 for albumin associated esterase activity.

Salivary proteins and microorganisms attach to restorative materials in the oral cavity [35-38]. Growth of S. mutans on resin composites has been known to roughen the surface of these restorative materials [39], and more recently S. mutans were shown to have esterolytic activity at levels that degrade resin composites [3]. Therefore, any means that may reduce esterolytic attack and alter the nature of protein presentation at the surface may potentially improve the longevity of the restorative material.

In the current study, the fluoro-chains incorporated were unable to reduce bacterial adhesion in vitro, with no significant $(p>0.05)$ difference in CFU count observed between the fluorinated and non-fluorinated surfaces. Adhered bacteria were removed from the surface by sonication using an ultrasonic bath, a technique commonly used for dislodging bacterial aggregates through physical, chemical and mechanical effects of acoustic cavitation, with the use of moderate frequencies between $\sim 20$ and $40 \mathrm{kHz}$ [40]. Although these polymer surfaces were unable to reduce bacterial adhesion, the presence of fluoro-groups can still provide a means for increasing the hydrophobicity of the corresponding resin composite, thereby altering the hydrophobic nature of the adsorbed protein layer and potentially modulating hydrolytic degradation in the wet oral environment. The latter findings warrant ongoing studies with these materials including studying the nature of bacterial derived esterase activities as a result of the influence that the fluorinated materials had on the protein interaction with monomer components and their polymers.

\section{Conclusions}

We have shown that incorporation of fluoro-chemistry into the monomers is not sufficient to eliminate protein and bacterial adhesion onto polymerized resins. However, such chemistry can be used to alter the nature of the interactions of proteins with these polymers, and specifically influence the nature of hydrophobic groups presented at the surface from the materials and the adhered proteins. This combination of fluorinated and urethane chemistry influences the nature of monomer stability against hydrolytically active protein catalysts, which may ultimately improve the longevity of polymerized composites generated from these monomers, when applied within the oral environment.

Supplementary Materials: The following are available online at www.mdpi.com/2073-4360/9/8/365/s1.

Acknowledgments: This research was supported by the Natural Science and Engineering Research Council of Canada (NSERC) Discovery grant \#360520. Yasaman Delaviz was funded by NSERC Alexander Graham Bell Canada Graduate Scholarship (NSERC CGS-D).

Author Contributions: Yasaman Delaviz, Meilin Yang, and J. Paul Santerre conceived and designed the experiments; Yasaman Delaviz and Meilin Yang performed the experiments; Yasaman Delaviz, Meilin Yang, and J. Paul Santerre analyzed the data; Yasaman Delaviz, Meilin Yang, and J. Paul Santerre contributed materials; and Yasaman Delaviz, Meilin Yang, and J. Paul Santerre wrote the paper.

Conflicts of Interest: The authors declare no conflict of interest.

\section{References}

1. Heintze, S.D.; Rousson, V. Clinical Effectiveness of Direct Class II Restorations-A Meta-Analysis. J. Adhes. Dent. 2012, 14, 407-431. [CrossRef] [PubMed] 
2. Finer, Y.; Santerre, J.P. Salivary Esterase Activity and Its Association with the Biodegradation of Dental Composites. J. Dent. Res. 2004, 83, 22-26. [CrossRef] [PubMed]

3. Bourbia, M.; Ma, D.; Cvitkovitch, D.G.; Santerre, J.P.; Finer, Y. Cariogenic Bacteria Degrade Dental Resin Composites and Adhesives. J. Dent. Res. 2013, 92, 989-994. [CrossRef] [PubMed]

4. Cai, K.; Delaviz, Y.; Banh, M.; Guo, Y.; Santerre, J.P. Biodegradation of Composite Resin with Ester Linkages: Identifying Human Salivary Enzyme Activity with a Potential Role in the Esterolytic Process. Dent. Mater. 2014, 30, 848-860. [CrossRef] [PubMed]

5. Jaffer, F.; Finer, Y.; Santerre, J.P. Interactions between Resin Monomers and Commercial Composite Resins with Human Saliva Derived Esterases. Biomaterials 2002, 23, 1707-1719. [CrossRef]

6. Finer, Y.; Santerre, J.P. The Influence of Resin Chemistry on a Dental Composite's Biodegradation. J. Biomed. Mater. Res. A 2004, 69, 233-246. [CrossRef] [PubMed]

7. Liu, D.; Liu, F.; He, J.; Lassila, L.V.J.; Vallittu, P.K. Synthesis of a Novel Tertiary Amine Containing Urethane Dimethacrylate Monomer (UDMTA) and Its Application in Dental Resin. J. Mater. Sci. Mater. Med. 2013, 24, 1595-1603. [CrossRef] [PubMed]

8. Moszner, N.; Fischer, U.K.; Angermann, J.; Rheinberger, V. A Partially Aromatic Urethane Dimethacrylate as a New Substitute for Bis-GMA in Restorative Composites. Dent. Mater. 2008, 24, 694-699. [CrossRef] [PubMed]

9. Buruiana, T.; Melinte, V.; Aldea, H.; Pelin, I.M.; Buruiana, E.C. A New Fluorinated Urethane Dimethacrylate with Carboxylic Groups for Use in Dental Adhesive Compositions. Mater. Sci. Eng. C Mater. Biol. Appl. 2016, 62, 96-104. [CrossRef] [PubMed]

10. Park, J.G.; Ye, Q.; Topp, E.M.; Misra, A.; Spencer, P. Water Sorption and Dynamic Mechanical Properties of Dentin Adhesives with a Urethane-Based Multifunctional Methacrylate Monomer. Dent. Mater. 2009, 25, 1569-1575. [CrossRef] [PubMed]

11. Kerby, R.E.; Knobloch, L.A.; Schricker, S.; Gregg, B. Synthesis and Evaluation of Modified Urethane Dimethacrylate Resins with Reduced Water Sorption and Solubility. Dent. Mater. 2009, 25, 302-313. [CrossRef] [PubMed]

12. Li, T.; Craig, R.G. Synthesis of Fluorinated Bis-GMA and Its Use with Other Fluorinated Monomers to Formulate Hydrophobic Composites. J. Oral Rehabil. 1996, 23, 158-162. [CrossRef] [PubMed]

13. Wang, G.; Culbertson, B.M.; Xie, D.; Seghi, R.R. Effect of Fluorinated Triethylene Glycol Dimethacrylate on the Properties of Unfilled, Light-Cured Dental Resins. J. Macromol. Sci. A 1999, 36, 237-252. [CrossRef]

14. Melinte, V.; Buruiana, T.; Chibac, A.; Mares, M.; Aldea, H.; Buruiana, E.C. New Acid BisGMA Analogs for Dental Adhesive Applications with Antimicrobial Activity. Dent. Mater. 2016, 32, e314-e326. [CrossRef] [PubMed]

15. Kovalchuk, N.M.; Trybala, A.; Starov, V.; Matar, O.; Ivanova, N. Fluoro- vs. Hydrocarbon Surfactants: Why Do They Differ in Wetting Performance? Adv. Colloid Interface Sci. 2014, 210, 65-71. [CrossRef] [PubMed]

16. Zhu, P.; Meng, W.; Huang, Y. Synthesis and Antibiofouling Properties of Crosslinkable Copolymers Grafted with Fluorinated Aromatic Side Chains. RSC Adv. 2017, 7, 3179-3189. [CrossRef]

17. Thorpe, A.A.; Peters, V.; Smith, J.R.; Nevell, T.G.; Tsibouklis, J. Poly (Methylpropenoxyfluoroalkylsiloxane)s: A Class of Fluoropolymers Capable of Inhibiting Bacterial Adhesion onto Surfaces. J. Flour. Chem. 2000, 104, 37-45. [CrossRef]

18. Bao, Q.; Nishimura, N.; Kamata, H.; Furue, K.; Ono, Y.; Hosomi, M.; Terada, A. Antibacterial and Anti-biofilm Efficacy of Fluoropolymer Coating by a 2,3,5,6-Tetrafluoro-p-phenylenedimethanol Structure. Colloids Surf. B 2017, 151, 363-371. [CrossRef] [PubMed]

19. Tsibouklis, J.; Stone, M.; Thorpe, A.A.; Graham, P.; Peters, V.; Heerlien, R.; Smith, J.R.; Green, K.L.; Nevell, T.G. Preventing Bacterial Adhesion onto Surfaces: The Low-Surface-Energy Approach. Biomaterials 1999, 20, 1229-1235. [CrossRef]

20. Gyo, M.; Nikaido, T.; Okada, K.; Yamauchi, J.; Tagami, J.; Matin, K. Surface Response of Fluorine Polymer-incorporated Resin Composites to Cariogenic Biofilm Adherence. Appl. Environ. Microbiol. 2008, 74, 1428-1435. [CrossRef] [PubMed]

21. Schweikl, H.; Hiller, K.-A.; Carl, U.; Schweiger, R.; Eidt, A.; Ruhl, S.; Müller, R.; Schmalz, G. Salivary Protein Adsorption and Streptococccus gordonii Adhesion to Dental Material Surfaces. Dent. Mater. 2013, 29, 1080-1089. [CrossRef] [PubMed] 
22. Yang, M.; Santerre, J.P. Synthesis, characterization and evaluation of biostable divinyl monomers for use in dental resin. In Proceedings of the 9th World Biomaterial Congress, Chengdu, China, 1-5 June 2012.

23. Lin, B.A.; Jaffer, F.; Duff, M.D.; Tang, Y.W.; Santerre, J.P. Identifying Enzyme Activities within Human Saliva Which are Relevant to Dental Resin Composite Biodegradation. Biomaterials 2005, 26, 4259-4264. [CrossRef] [PubMed]

24. Shokati, B.; Tam, L.E.; Santerre, J.P.; Finer, Y. Effect of Salivary Esterase on the Integrity and Fracture Toughness of the Dentin-resin Interface. J. Biomed. Mater. Res. B 2010, 94, 230-237. [CrossRef] [PubMed]

25. Silva, Z.S., Jr.; Huang, Y.Y.; de Freitas, L.F.; França, C.M.; Botta, S.B.; Ana, P.A.; Mesquita-Ferrari, R.A.; Santos Fernandes, K.P.; Deana, A.; Lima Leal, C.R.; et al. Papain Gel Containing Methylene Blue for Simultaneous Caries Removal and Antimicrobial Photoinactivation Against Streptococcus mutans Biofilms. Sci. Rep. 2016, 6, 33270. [CrossRef] [PubMed]

26. Wessel, S.W.; van ser Mei, H.C.; Morando, D.; Slomp, A.M.; van de Belt-Gritter, B.; Maitra, A.; Busscher, H.J. Quantification and Qualification of Bacteria Trapped in Chewed Gum. PLoS ONE 2015, 10, e0117191. [CrossRef] [PubMed]

27. Krafft, M.P.; Riess, J.G. Chemistry, Physical Chemistry, and Uses of Molecular Fluorocarbon-Hydrocarbon Diblocks, Triblocks, and Related Compounds-Unique "Apolar" Components for Self-Assembled Colloid and Interface Engineering. Chem. Rev. 2009, 109, 1714-1792. [CrossRef] [PubMed]

28. Hagio, M.; Kawaguchi, M.; Motokawa, W.; Miyazaki, K. Degradation of Methacrylate Monomers in Human Saliva. Dent. Mater. 2006, 25, 241-246. [CrossRef]

29. Vogler, E.A. Structure and Reactivity of Water at Biomaterial Surfaces. Adv. Colloid Interface Sci. 1998, 74, 69-117. [CrossRef]

30. Schweikl, H.; Hartmann, A.; Hiller, K.A.; Spagnuolo, G.; Bolay, C.; Brockhoff, G.; Schmalz, G. Inhibition of TEGDMA and HEMA-induced Genotoxicity and Cell Cycle Arrest by N-acetylcysteine. Dent. Mater. 2007, 23, 688-695. [CrossRef] [PubMed]

31. Roach, P.; Farrar, D.; Perry, C.C. Interpretation of Protein Adsorption: Surface-Induced Conformational Changes. J. Am. Chem. Soc. 2005, 127, 8168-8173. [CrossRef] [PubMed]

32. Xu, L.C.; Siedlecki, C.A. Effects of Surface Wettability and Contact Time on Protein Adhesion to Biomaterial Surfaces. Biomaterials 2007, 28, 3273-3283. [CrossRef] [PubMed]

33. Stallard, C.P.; McDonnell, K.A.; Onayemi, O.D.; O'Gara, J.P.; Dowling, D.P. Evaluation of Protein Adsorption on Atmospheric Plasma Deposited Coatings Exhibiting Superhydrophilic to Superhydrophobic Properties. Biointerphases 2012, 7, 31. [CrossRef] [PubMed]

34. Sakurai, Y.; Ma, S.F.; Watanabe, H.; Yamaotsu, N.; Hirono, S.; Kurono, Y.; Kragh-Hansen, U.; Otagiri, M. Esterase-Like Activity of Serum Albumin: Characterization of Its Structural Chemistry Using P-Nitrophenyl Esters as Substrates. Pharm. Res. 2004, 21, 285-292. [CrossRef] [PubMed]

35. Hannig, M. Transmission Electron Microscopic Study of In Vivo Pellicle Formation on Dental Restorative Materials. Eur. J. Oral Sci. 1997, 105, 422-433. [CrossRef] [PubMed]

36. Hannig, M. Transmission Electron Microscopy of Early Plaque Formation on Dental Materials in vivo. Eur. J. Oral Sci. 1999, 107, 55-64. [CrossRef] [PubMed]

37. Spencer, P.; Ye, Q.; Misra, A.; Goncalves, S.; Laurence, J. Proteins, Pathogens, and Failure at the Composite-Tooth Interface. J. Dent. Res. 2014, 93, 1243-1249. [CrossRef] [PubMed]

38. Konishi, N.; Torii, Y.; Kurosaki, A.; Takatsuka, T.; Itota, T.; Yoshiyama, M. Confocal Laser Scanning Microscopic Analysis of Early Plaque Formed on Resin Composite and Human Enamel. J. Oral Rehabil. 2003, 30, 790-795. [CrossRef] [PubMed]

39. Beyth, N.; Bahir, R.; Matalon, S.; Domb, A.J.; Weiss, E.I. Streptococcus mutans Biofilm Changes Surface-Topography of Resin Composites. Dent. Mater. 2008, 24, 732-736. [CrossRef] [PubMed]

40. Webber, B.; Canova, R.; Esper, L.M.; Perdoncini, G.; Pinheiro Do Nascimento, V.; Pilotto, F.; Ruschel dos Sanntos, L.; Rodrigues, L.B. The Use of Vortex and Ultrasound Techniques for the in vitro Removal of Salmonella spp. Biofilms. Acta Sci. Vet. 2015, 43, 1332.

(C) 2017 by the authors. Licensee MDPI, Basel, Switzerland. This article is an open access article distributed under the terms and conditions of the Creative Commons Attribution (CC BY) license (http:/ / creativecommons.org/licenses/by/4.0/). 